\title{
Relação entre a Renda Mensal e o Desejo de Ter Filhos Procurados no Parceiro Afetivo por Homens e Mulheres Homossexuais e Heterossexuais
}

\author{
Alda Loureiro Henriques* \\ Karina Nunes Leão* \\ Myenne Mieko Ayres Tsutsumi" \\ Universidade Federal do Pará, Belém, PA, Brasil
}

\begin{abstract}
RESUMO
A eficácia do desempenho sexual, de um modo geral, depende de uma seleção rigorosa de parceiros feita pelos membros de cada espécie. Entre os humanos, o critério financeiro é um dos aspectos que caracterizam a diferença sexual na seleção de parceiros. Contudo, o comportamento sexual não pode ser definido apenas pelos aspectos característicos de pessoas heterossexuais, pois também existem relacionamentos homossexuais. A partir desta perspectiva, investigou-se, através de um website, as preferências de homossexuais e heterossexuais por renda mensal e desejo de ter filhos no parceiro. Constatou-se que os heterossexuais desejam mais ter filhos do que os homossexuais. Além disso, para ambas as orientações, a "renda mensal" não demonstrou ser um critério seletivo na hora de escolher um parceiro.
\end{abstract}

Palavras-chave: orientação sexual; renda mensal; desejo de ter filhos; gênero.

\section{ABSTRACT \\ Relation Between Sexual Partner's Income and Their Desire to Have Children Wanted by Homosexual and Heterosexual Men and Women}

The effectiveness of sexual performance generally depends on a selection made by rigorous partners members of each species. Among humans, the financial test is one of the aspects that characterize the sexual difference in the selection of partners. However, sexual behavior cannot be defined only by the characteristic aspects of heterosexual people, because there are also homosexual relationships. From this perspective, it was investigated, through a website, the preferences of homosexual and heterosexual by monthly income and partner's desire to have children. It was found that heterosexual's desire to have children is bigger than homosexuals. In addition, for both orientations, the "monthly income" not proved to be a selective criterion when choosing a partner.

Keywords: sexual orientation; monthly income; desire to have children; gender.

O conceito de seleção sexual é imprescindível quando se aborda a questão da procriação regida pela natureza. Segundo Darwin, a seleção sexual é um mecanismo que age diferencialmente sobre os organismos e sua reprodução. Diante disso, este conceito caracteriza-se como sendo um dos principais aspectos teóricos na compreensão do comportamento sexual de homens e mulheres na escolha de parceiro.
Conforme a Teoria do Investimento Parental, proposta por Trivers (1972), os indivíduos devem escolher e competir por parceiros que possuam características ou vantagens reprodutivas essenciais para os papéis a serem desempenhados. Dessa forma, entre os humanos, aspectos como renda financeira e status socioeconômico seriam de grande valia, dada sua importância na garantia de sobrevivência da prole, por exemplo, para as mulheres no momento em que esco-

\footnotetext{
Endereço para correspondência: Alda Loureiro Henriques - aldalhenriques@gmail.com

Endereço para correspondência: Karina Nunes Leão - ka.rita.nunes@hotmail.com

Endereço para correspondência: Myenne Mieko Ayres Tsutsumi - myennechan@hotmail.com
} 
lhem seus futuros parceiros. Este cenário se deve, principalmente, porque seleção de parceiros para a mulher estaria fundamentalmente relacionada à sobrevivência de sua futura prole (DeWall \& Maner, 2008; Furnham, 2009; Buunk, Dijkrsta, Fetchenhauer \& Kenrick, 2002; Bailey, Gaulin, Agyei, \& Glaude, 1994; Moore, Cassidy, \& Perrett, 2010).

Contudo, as preferências características de homens e mulheres na escolha do parceiro e sua ligação com a procriação parecem sofrer uma ruptura quando se leva em consideração o comportamento dos homossexuais (Sommer \& Vasey, 2006). O estudo e a compreensão dos comportamentos homossexuais quanto a escolha do parceiro é importante por vários motivos, entre os quais, podemos destacar, a contribuição para a melhor compreensão das escolhas dos próprios heterossexuais, com o intuito de verificar como homens e mulheres se diferenciam, seja filogenética ou ontogeneticamente, como discutem Bailey et al. (1994) e VanderLaan (2007). Além disso, não é possível estender a teoria da seleção sexual para todos os aspectos relativos à escolha do parceiro, surgindo, assim, diversos quadros teóricos que procuram abranger tal compreensão. A 'teoria da troca social' (social exchange theory) e aquelas que se baseiam em aspectos fisiológicos e psicológicos são exemplos dessas teorias alternativas à seleção sexual e que não são excludentes entre si (Smith, Konik, \& Tuve, 2011).

Quanto aos aspectos fisiológicos, a discussão acerca das mulheres lésbicas vem à tona quando o assunto é maternidade, principalmente pelo fato do bebê humano exigir um longo período de investimento parental, cuja consequência foi a extrema seletividade da fêmea heterossexual (Brito, Junior, \& Henriques, 2009). Apesar do caso de mães lésbicas ser discutido na literatura (Falk, 1989; Pies, 1989; Flaks, Fisher, Marterpasqua, \& Joseph, 1995), a relação entre a maternidade destas mulheres e suas preferências por parceiras com alto status socioeconômico necessita de mais estudos, visto que não se sabe conclusivamente se há um padrão comportamental global distintivo destas mulheres acerca do comportamento de escolha da parceira (Henriques, Leão, \& Tsutsumi, 2013), assim como sobre as influências biológicas e culturais em suas escolhas. Entretanto, está sendo bem explorada a hipótese da influência da exposição precoce ou maior a andrógenos do bebê durante o período uterino (Brown, Finn, Cooke, \& Breedlove, 2002).
Os estudos acerca das famílias formadas por casais homossexuais se tornam cada vez mais numerosos na literatura (Grossi, 2003; Mallon, 2007; Patterson, 2006; Zambrano, 2006). Contudo, a rejeição social com relação a este novo módulo familiar, muitas vezes baseada em crenças não fundamentadas, ainda está presente na sociedade. $\mathrm{O}$ estudo acerca da seleção de parceiros entre os homossexuais em comparação a dos heterossexuais se faz necessário para que as diferenças e semelhanças do comportamento de ambos sejam conhecidas e identificadas cientificamente, inclusive no que diz respeito ao desejo de ter filhos. A intenção de criar/ter filhos pode estar implicada na determinação de inúmeros aspectos do comportamento de escolha do parceiro. Conhecer o perfil dos homossexuais quanto a este fato é importante também para traçar as características desse novo quadro familiar.

Outro ponto digno de menção deste trabalho diz respeito à metodologia utilizada. Diferentemente dos dados coletados através de questionários utilizados em grande parte dos estudos, os dados coletados através de sites na internet podem apontar algumas divergências acerca de certas características. Esta possibilidade se deve ao fato de que a internet é uma ferramenta utilizada pelos próprios participantes com o intuito de atrair um companheiro(a), de forma mais direta e motivada.

A partir dos questionamentos que relacionam a orientação sexual das mulheres, sua escolha pela maternidade e o comportamento de escolha do parceiro, a relação entre o desejo de ter filhos e a preferência por renda mensal do companheiro são importantes para aprofundar o conhecimento acerca das diferentes orientações sexuais, bem como verificar se seus perfis comportamentais são fruto de traços biológicos e evolutivos ou são fundamentalmente culturais ou pessoais. Dessa forma, os objetivos deste trabalho foram: analisar se a preferência de homens e mulheres homossexuais e heterossexuais pela "renda mensal" do parceiro e o seu "desejo de ter filhos" são critérios seletivos na escolha do parceiro; verificar se as preferências dos homossexuais para estes dois aspectos se assemelham às preferências dos heterossexuais e, por fim, verificar se existe interação entre esses dois aspectos. 


\section{MÉTODO}

\section{Participantes}

Foram coletados dados de 160 usuários de um website para relacionamentos afetivos, sendo 40 homens e 40 mulheres heterossexuais e 40 homens e 40 mulheres homossexuais (sendo a orientação sexual definida por autodeclaração), com idades variando entre 20 e 35 anos entre as mulheres, e entre 20 e 46 anos entre os homens. Esta diferença nas faixas etárias de homens e mulheres deveu-se ao fato de que, entre as mulheres, quanto maior a idade, maior a probabilidade de uma gravidez de alto risco (Senesi, Tristão, Andrade, Krajden, Junior, \& Nascimento, 2004), o que acaba resultando em um desejo cada vez menor de ter filhos por parte de mulheres na faixa dos 40 anos, sendo este um importante item a ser avaliado neste estudo. Em contrapartida, entre os homens é mais comum ter filhos em uma faixa etária mais alta do que as mulheres, visto que eles preferem e se casam, na maioria das vezes, com mulheres mais novas (Otta, Queiroz, Campos, Silva, \& Silveira, 1998; Henriques, Leão, \& Tsutsumi, 2011). Além do critério idade, outros aspectos levados em consideração para a inclusão dos participantes neste estudo foram: apresentar perfis com fotografia, informar sua própria renda mensal e o seu desejo de ter ou não filhos e indicar sua preferência por renda mensal e sobre o desejo que o parceiro deve manifestar acerca de ter filhos. Contudo, foram necessárias algumas alterações nesses critérios quanto à informação da renda mensal do usuário, pois como o site proporciona a possibilidade de cada usuário mantê-la em sigilo, esta condição também foi aceita nesta pesquisa.

\section{Ambiente}

Os dados foram obtidos em um website público para relacionamentos afetivos, para pessoas que moram no Brasil, os quais poderiam ser acessados por meio de cadastro. Foi necessária a conexão por Internet para a realização da coleta de dados.

\section{Procedimento}

Foram criados perfis fictícios e neutros no website para ter acesso aos perfis dos usuários que se encaixavam nos critérios estipulados para os participantes desta pesquisa. Os dados coletados foram organizados e sistematizados em uma planilha para a análise e tratamento.

\section{RESULTADOS}

\section{Desejo do usuário de ter filhos}

A partir dos objetivos propostos, foi possível verificar que a preferência dos indivíduos homossexuais quanto ao "desejo de ter filhos" não se assemelha à preferência dos heterossexuais. Dentre as mulheres homossexuais (MHOM), 45\% disseram "sim", enquanto que entre os homens homossexuais (HHOM), apenas $15 \%$ manifestaram esse mesmo desejo. Para os heterossexuais, o desejo de ter filhos apresentou uma taxa mais alta: 90\% das mulheres (MHET) e 92,5\% dos homens (HHET) afirmaram que desejavam ter filhos. Dessa forma, é possível observar que os homossexuais não seguiram o mesmo padrão dos heterossexuais quanto ao "desejo de ter filhos", embora as mulheres, tanto homo quanto hétero, tenham manifestado esse desejo mais frequentemente do que os homens de ambas as orientações sexuais investigadas (Figura 1). 


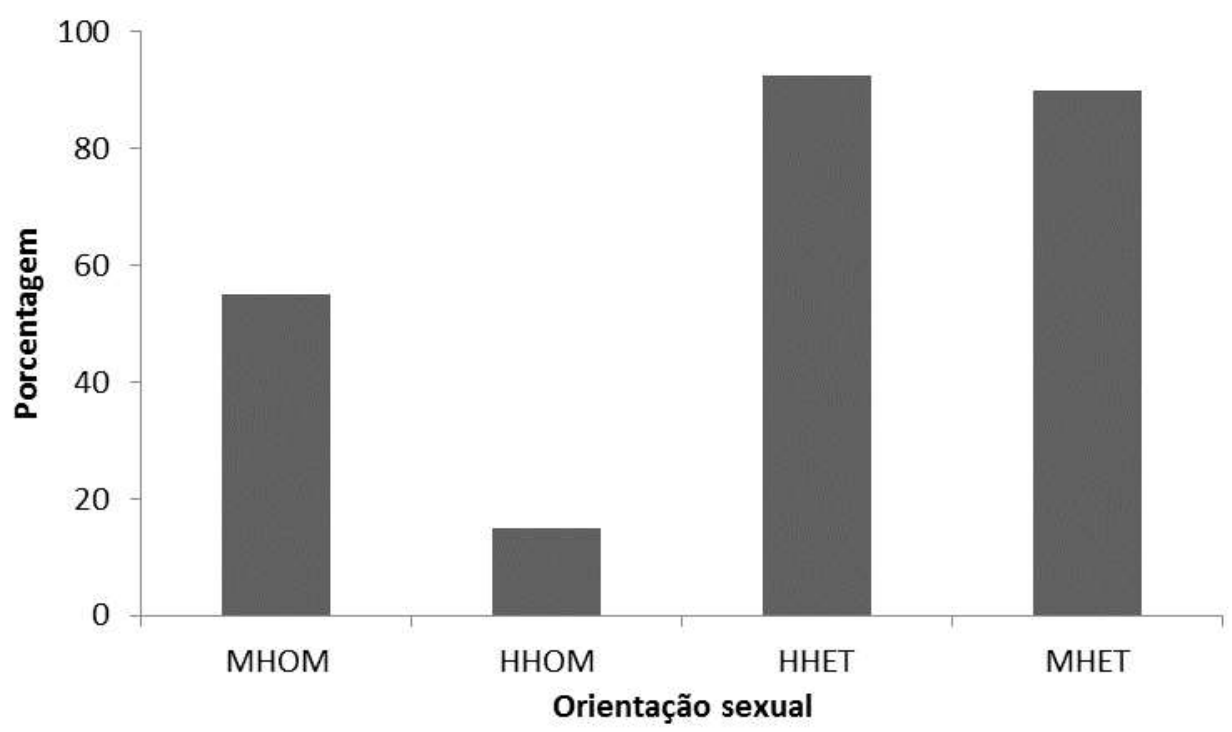

Figura 1. Frequência relativa de respostas "sim" referente ao "desejo de ter filhos" dos usuários do website. MHOM: Mulheres Homossexuais; HHOM: Homens Homossexuais; HHET: Homens Heterossexuais; MHET: Mulheres Heterossexuais.

\section{Renda mensal pretendida pelo usuário no parceiro}

Quanto à renda mensal do parceiro, o usuário poderia escolher entre as seguintes cinco categorias oferecidas pelo site, em reais: até 1000 , entre 1001 e 2500 , entre 2501 e 5000 , entre 5001 e 10000 e "indiferente". Como pode ser visualizada na figura 2 , a categoria "indiferente" obteve escores bastantes superiores às demais para todos os subgrupos. Entre os homens, esta escolha correspondeu à $87,5 \%$. Entre as mulheres, $72,5 \%$ das homossexuais e $82,5 \%$ das heterossexuais se declararam indiferentes quanto à renda do parceiro (a).

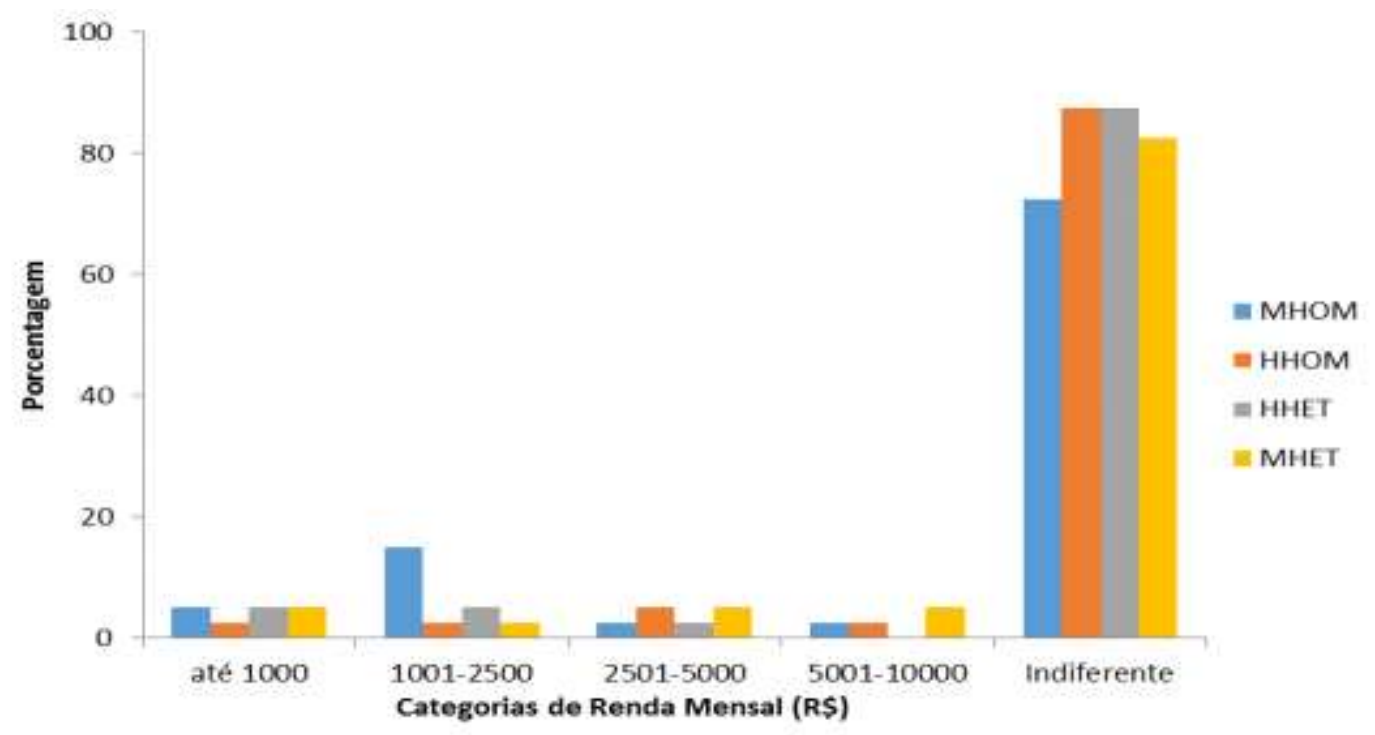

Figura 2. Frequência relativa das preferências dos participantes usuários por categorias de "renda mensal" recebida pelo provável parceiro. MHOM: Mulheres Homossexuais; HHOM: Homens Homossexuais; HHET: Homens Heterossexuais; MHET: Mulheres Heterossexuais. 
Até aqui, é tentador dizer que o aspecto "renda mensal" não é um critério seletivo para escolher um parceiro, e isso tanto entre os heterossexuais quanto entre os homossexuais. Diferentemente do que foi encontrado na literatura (DeWall\&Maner, 2008; Furnham, 2009; Buunk, Dijkrsta, Fetchenhauer, \& Kenrick, 2002, Bailey, Gaulin, Agyei, \& Glaude, 1994; Moore, Cassidy, \& Perrett, 2010), para os participantes desta pesquisa e com relação ao aspecto seleção de parceiros versus renda mensal, supõe-se que a renda do parceiro não tem muita importância na hora de se escolher um namorado(a). Isso pôde ser observado através da grande manifestação de "indiferente" em relação à renda mensal de um possível parceiro. Contudo, sugere-se a metodologia utilizada neste trabalho pode ter contribuído para este resultado, visto que num site de relacionamentos afetivos, as preferências dos usuários estão sendo declaradas diretamente ao candidato a parceiro (a) e, muito provavelmente, declarar interesse por determinada faixa de renda, principalmente se ela for elevada, pode conotar interesses específicos por este atributo e, assim, não ser uma boa estratégia para ser exposta publicamente.

\section{Desejo de ter filhos (relação entre usuário e parceiro)}

No site utilizado para a coleta de dados além de ser investigado o desejo do usuário de ter filhos, investigou-se também se ele escolhia preferencialmente quem desejasse também ter filhos. Entre as opções de respostas oferecidas pelo site encontrava-se "sim", "não" e "indiferente". Como critério para julgar se o "desejo de ter filhos" do parceiro procurado é seletivo ou não, foram agrupadas as respostas coincidentes (' $\mathrm{sim} / \mathrm{sim}$ ' - sim, o participante quer ter filho/sim, seu parceiro também deve querer ter filho; 'não/não' não, o usuário não quer ter filho/não, seu parceiro também não deve querer ter filho) como um sistema afirmativo de seleção do usuário, enquanto respostas divergentes ('sim/indiferente'; 'não/indiferente') foram agrupadas como categorias de não-seletividade por parte do participante, ou seja, não haveria relação entre o desejo de ter ou não filho do participante e o mesmo desejo por parte do parceiro procurado.

As respostas coincidentes representaram a maioria das escolhas, tanto para os homossexuais quanto para os heterossexuais (Tabela 1). Entre aqueles que querem ter filhos e desejam que seus parceiros também o queiram $(\mathrm{sim} / \mathrm{sim})$, destacam-se as mulheres heterossexuais, com $72,5 \%$. Em seguida, estão os homens heterossexuais com $47,5 \%$, as mulheres homossexuais com $40 \%$ e, por fim, os homens homo com apenas $5 \%$ de usuários. A partir destes dados, é possível inferir que para as mulheres heterossexuais, principalmente, o parceiro desejar ter filhos é essencial para a escolha do parceiro, este aspecto constituindo-se em um critério de seleção.

$\begin{aligned} & \text { Tabela } 1 \\
& \text { Valores Absolutos e Porcentagens Relativos ao Desejo de Ter Filhos do Usuário e do Parceiro Buscado } \\
& \text { por Ele. N de Cada Categoria }=40\end{aligned}$
\begin{tabular}{ccccccccccc} 
Categorias & MHOM & $\%$ & HHOM & $\%$ & HHET & $\%$ & MHET & $\%$ \\
\hline Sim/Sim & 16 & 40 & 5 & 12,5 & 19 & 47,5 & 29 & 72,5 \\
Não/Não & 6 & 15 & 17 & 42,5 & 1 & 2,5 & 4 & 10 \\
Sim/Indif' & 6 & 15 & 1 & 2,5 & 18 & 45 & 7 & 17,5 \\
Não/Indif & 12 & 30 & 17 & 42,5 & 2 & 5 & 0 & 0 \\
\hline
\end{tabular}

Nota: ${ }^{1}$ Indiferente

Quanto às respostas divergentes, podem-se destacar as escolhas feitas pelos homens. Na maioria dos casos (45\%, Tabela 1) os HHET manifestam o desejo de ter filhos, mas em igual porcentagem se declararam indiferentes quanto ao desejo por filhos das parceiras que almejam (categoria sim/indif). Já entre os HHOM a não preferência por filhos e a indiferença quanto ao desejo do parceiro (não/indif) também demonstrou frequência alta $(42,5 \%)$. Esses dados sugerem que o "desejo de ter filhos" não é um critério essencial para a seleção de parceiros por parte dos homens, independente da orientação sexual, pois estes, majoritariamente, não manifestam uma clara preferência quanto a vontade ou desejo de seu parceiroa por uma futura 
prole, apesar de afirmarem que querem ter filhos (o primeiro "sim" da contabilidade).

\section{Renda Mensal (futuro parceiro) X Desejo de ter filhos (usuário)}

Para o terceiro e último objetivo deste trabalho, ou seja, verificar se existe interação entre a renda mensal do parceiro almejado e o desejo do usuário de ter filhos, os dados foram analisados através do programa estatístico SPSW 18, sendo utilizado o teste não paramétrico do qui-quadrado, considerando $\mathrm{p} \leq 0,05$ como nível de significância.

Tabela 2

Frequência Bruta e Percentual dos Usuários que Desejam ter Filhos

\begin{tabular}{lcc} 
& Sim/Filhos & $\%$ \\
MHOM & 22 & 55 \\
HHOM & 6 & 15 \\
HHET & 37 & 92,5 \\
MHET & 36 & 90 \\
\hline
\end{tabular}

Em seguida às respostas 'indiferente', as mulheres, 6,25\% dos usuários homens declararam desejar que o independente da orientação sexual, foram as que mais parceiro possua renda. se interessaram por esse quesito com 10,63\%. Já

Tabela 3
$\begin{aligned} & \text { Frequência Bruta e Percentual, por Orientação Sexual, dos Usuários que } \\
& \text { Desejam que Seus Parceiros Possuam Renda } \\
& \text { Sim/Renda }\end{aligned}$
\begin{tabular}{lcc}
\multicolumn{4}{c}{$\%$} \\
MHOM & 11 & 27,5 \\
HHOM & 5 & 12,5 \\
HHET & 5 & 12,5 \\
MHET & 6 & 15 \\
\hline
\end{tabular}

No entanto, a opção "indiferente" (Tabela 4), referente ao usuário do site não se importar com o fato do parceiro possuir renda ou não, foi a mais escolhida dentre os quatro grupos estudados. 63 usuárias mulhe- res, independente da orientação sexual, declararam não se importar com a renda dos seus parceiros (as) e 70 homens, independente da orientação sexual, são, também, indiferentes.

Tabela 4

Frequência Bruta e Porcentagem dos Usuários que Se Declararam Indiferentes Quanto ao Parceiro Ter ou Não Renda

Indiferente/Renda \%

\begin{tabular}{lrr} 
MHOM & 29 & 72,5 \\
HHOM & 35 & 87,5 \\
HHET & 35 & 87,5 \\
MHET & 34 & 85 \\
\hline
\end{tabular}


Foram feitas três comparações entre as três variáveis analisadas para verificar a possibilidade de interação entre elas: Desejo de que o parceiro possua algum tipo de renda e desejo do usuário de ter filhos; desejo do usuário de ter filhos e orientação sexual; e desejo de que o parceiro possua algum tipo de renda e a orientação sexual.

\section{- Desejo de que o parceiro possua algum tipo de renda e desejo do usuário de ter filhos}

Não foi verificada diferença estatisticamente significativa entre o desejo de que o parceiro possua algum tipo de renda e o desejo do usuário de ter filhos. Em outras palavras, o fato de o parceiro ter ou não renda não está relacionado com o desejo de ter filhos demonstrado pelo usuário.

\section{- Desejo do usuário de ter filhos e a sua orientação sexual}

Foi identificada uma diferença estatisticamente significativa entre o desejo de ter filhos e a orientação sexual $\left(x^{2}=68,17 ; p \leq 0,05\right)$. Ou seja, de acordo com os resultados, mais homens e mulheres hetero desejam ter filhos.

\section{- Desejo de que o parceiro possua algum tipo de renda e a orientação sexual do usuário}

Não foi verificada diferença estatisticamente significativa entre o desejo de que o parceiro possua algum tipo de renda e a orientação sexual. Esse dado sugere que homo e heterossexuais não foram específicos em relação ao tipo de renda que o parceiro desejado deve ter. Talvez isso seja reflexo de uma estratégia de seleção de parceiro marcada pelo mascaramento das verdadeiras intenções quando estas podem ser consideradas negativas, ou seja, não ser socialmente bem aceita, o que acabaria afugentando um possível parceiro.

\section{CONCLUSÃO}

A partir das análises feitas, podem-se constatar alguns fatos interessantes, como, por exemplo, a diferença entre os heterossexuais e os homossexuais quanto ao desejo de ter filhos, com os heterossexuais desejando mais ter filhos do que os homossexuais. E, dentre estas comparações, destacou-se o fato de que os homens homossexuais não foram desejosos de ter filhos. Foi possível verificar também que, tanto para heterossexuais quanto para os homossexuais, aspectos como "renda mensal", aparentemente, não demonstrou ser um critério seletivo na hora de escolher um parceiro. Por outro lado, o "desejo do parceiro(a) de ter filhos" demonstrou ser essencial, pelo menos para a faixa etária estudada, com destaque para a mulher heterossexual, que utilizou este como um critério de seleção de parceiro.

Não houve interação entre "renda mensal" e "desejo deter filhos", ou seja, a renda mensal não é um fator decisivo na hora de escolher um parceiro entre aqueles que provavelmente visam constituir uma família. É importante destacar que este cenário foi observado tanto entre os homossexuais quanto entre os heterossexuais. Entretanto, a metodologia de coleta de dados utilizada neste trabalho pode ter sido responsável por tal resultado. Em pesquisas feitas com questionários existe a garantia ao participante de que ninguém, além de pesquisadores, tomará conhecimento de suas respostas. O problema é que muitas vezes é pedido ao participante que se expresse em relação a um parceiro já existente, para o qual sentimentos negativos podem interferir no caso de se tratar de um relacionamento que esteja sofrendo algum desgaste. Já os dados disponíveis em websites, apesar de parecerem mais espontâneos, por serem públicos, podem justamente refletir um cuidado muito maior com as respostas em função da reação daquele a quem as informações são direcionadas, ou seja, o candidato a pretendente (Henriques, Tsutsumi, \& Leão, 2011b). Em compensação, os dados oferecidos por websites possuem seu lado positivo, pois além de representar o cenário mais direto de busca por parceiro no qual a própria motivação do usuário o levou a preencher todos os dados, a internet é uma ferramenta na qual o indivíduo não possui, em muitos casos, restrição quanto ao número de informações que ele pode oferecer e buscar. Dessa forma, a utilização de sites de relacionamento como uma estratégia utilizada para buscar e selecionar um parceiro pode também ser interessante para avaliar a aplicabilidade e os limites da Teoria da Estratégia Sexual (Dawson \& McIntosh, 2006), através de um ambiente original, embora virtual, de seleção de parceiros. 


\section{REFERÊNCIAS}

Bailey, J. M., Gaulin, S., Agyei, Y., \& Gladue, B. A. (1994). Effects of gender and sexual orientation on evolutionarily relevant aspects of human mating psychology. Journal of Personality and Social Psychology, 66, 1081-1093. doi :10.1037/0022-3514.66.6.1081

Brito, R. C. S., Júnior, M. D. S., \& Henriques, A. L. (2009). Critérios de escolha de parceira amorosa em mulheres climatérias e menopausadas. Revista do Nufen, 1(2), 5574.

Brown, W. M., Finn, C. J., Cooke, B. M., \& Breedlove, S. M. (2002). Differences in Finger Length Ratios Between Self-Identified "Butch" and "Femme" Lesbians. Archives of Sexual Behavior, 31(1), 123-127. doi: 10.1023/A:1014091420590

Buunk, B. P., Dijkstra, P., Fetchenhauer, D., \& Kenrick, D. T. (2002). Age and gender differences in mate selection criteria for various involvement levels. Personal relationships, 9, 271-278.doi: 10.1111/1475-6811.00018

Dawson, B. L. \& McIntosh, W. D. (2006). Sexual Strategies Theory and Internet Personal Advertisements. $C y$ berPsychology and Behavior, 9(5), 614-617.

DeWall, C. N. \& Maner, J. K. (2008). High Status Men (But Not Women) Capture the Eye of the Beholder. Evolutionary Psychology, 6(2), 328-341.

Falk, P. J. (1989). Lesbian mothers: Psychosocial assumptions in family law. American Psychologist, 44(6), 941947. doi:10.1037/0003-066X.44.6

Flaks, D. K., Ficher, I., Marterpasqua, F., \& Joseph, G. (1995). Lesbians Choosing Motherhood: A Comparative Study of Lesbian and Heterosexual Parents and Their Children. Developmental Psychology, 31(1), 105-114. doi: 10.1037/0012-1649.31.1.105

Furnham, A. (2009). Sex differences in mate selection preferences. Personality and Individual Differences, 47, 262267. doi: $10.1016 /$ j.paid.2009.03.013

Grossi, M. P. (2003). Gênero e parentesco: famílias gays e lésbicas no Brasil. Cadernos Pagu, Campinas, Unicamp, n. 21, p. 261-280, 2003. Recuperado de http://www.scie lo.br/pdf/cpa/n21/n21a11.pdf

Henriques, A. L., Leão, K. N., \& Tsutsumi, M. M. A. (2013). Estudo comparativo das preferências por idade, altura e peso de homossexuais e heterossexuais na seleção de parceiros. Boletim - Academia Paulista de Psicologia, v. 33, p. 64-78.

Henriques, A. L., Tsutsumi, M. M. A., \& Leão, K. N. (2011). Existem padrões de preferência por atributos entre homossexuais e heterossexuais na busca por parcei$r o$ ? Manuscrito submetido para publicação.

Mallon, G. P. (2007). Assessing Lesbian and Gay Prospective Foster and Adoptive Families: A Focus on the
Homestudy Process. Child Welfare 86(2): 67-87. Recuperado de http://www.california-adoption.org/Documen ts/LGBT_homestudies.pdf

Moore, F., Cassidy, C., \& Perrett, D. I. (2010). The effects of control of resources on magnitudes of sex differences in human mate preferences. EvolutionaryPsychology, 8(4), 720-735. Recuperado de http://www.epjournal.net/ wp-content/uploads/EP08720735.pdf .

Otta, E., Queiroz, R. S., Campos, L. S., Silva, M. W. D., \& Silveira, M. T. (1998). Escolha de parceiros heterossexuais: um estudo de proclamas de casamento. Interação em psicologia, 2, 97-112. Recuperado de http://ojs.c3sl. ufpr.br/ojs2/index.php/psicologia/article/view/7649/5455

Patterson, C. J. (1992). Children of lesbian and gay parents. Child Development, 63, 1025-1042. doi: 10.1111/j.14678624.1992.tb01679.

Pies, C. A. (1989). Lesbians and the choice to parent. Marriage and Family Review, 14, 137-154. doi: 10.1300/ J002v14n03_07

Senesi, L. G., Tristão, E. G., Andrade, R. P.; Krajden, M. L., Junior, F. C. O., \& Nascimento, D. J. (2004). Morbidade e Mortalidade Neonatais Relacionadas à Idade Materna Igual ou Superior a 35 Anos, segundo a Paridade. Revista Brasileira de Ginecologia e Obstretícia, 26(6), p. 477-482. Recuperado de http://dx.doi.org/10.1590/ S0100-72032004000600009

Smith, C. A., Konik, J. A., \& Tuve, M. V. (2011). In Search of Looks, Status, or Something Else? Partner Preferences Among Butch and Femme Lesbians and Heterosexual Men and Women. Sex Roles, 64, 658-668. doi: 10.1007/ s11199-010-9861-8

Sommer, V. \& Vasey, P. L. (2006). Homosexual Behavior in Animals. Cambridge University Press.

Trivers, R. L. (1972). Parental investment and sexual selection. In Sexual Selection and the Descent of Man, 1871 1971. (ed. B. Campbell. Chicago). EUA: Aldine Publishing Company. doi: 10.1002/ajpa.1330400226

VanderLaan, D. P. (2007). Elucidating the origins of heterosexual sex differences in mating psychology by examining the behavior of homosexual men and women. (Unpublished master's thesis). University of Lethbridge, Alberta.

Zambrano, E. (2006). Parentalidades "Impensáveis": pais/mães homossexuais, travestis e transexuais. Horizontes Antropológicos, 26, 123-147. Recuperado de http://dx.doi.org/10.1590/S0104-71832006000200006

Recebido em: 04/10/2013 Última Revisão em: 10/12/2014 Aceito em: 20/03/2015 